\title{
Articaína: aspectos moleculares e aplicabilidade na clínica odontológica
}

\author{
Articaine: molecular aspects and applicability in the dental clinic \\ Articaína: aspectos moleculares y aplicabilidad en clínica dental
}

\section{Resumo}

A anestesia local é comumente utilizada na odontologia para realização de procedimentos que envolvem dor. Os anestésicos locais atualmente disponíveis são pertencentes ao grupo amida e atuam bloqueando, temporariamente, a passagem de impulso nervoso. A articaína, apesar de ser um anestésico relativamente novo em relação aos demais, vem sendo amplamente utilizada, mostrando diversos benefícios clínicos; contudo, é um fármaco comumente associado a episódios de parestesia não cirúrgica. O objetivo deste trabalho foi revisar a literatura acerca da utilização da articaína na odontologia, destacando suas características clínicas e moleculares e as possíveis complicações decorrentes do seu uso. O presente trabalho foi realizado por meio de uma pesquisa bibliográfica de artigos científicos e livros sobre o tema, buscando conhecer as supostas vantagens e desvantagens do uso da articaína nos procedimentos odontológicos. Em relação às vantagens, apresenta alta capacidade de difusão para o interior da célula nervosa, o que possibilita altas taxas de sucesso e curto tempo de latência, além de curto tempo de meia-vida e duração de ação mais prolongada, em comparação com os demais anestésicos locais. No que se refere às supostas desvantagens, a articaína tem sido comumente associada a um risco aumentado de parestesia não cirúrgica, provavelmente por conta da maior concentração em que é comercializada, a 4\%. Entretanto, não existem evidências suficientes para confirmar esta relação e nem para refutar. Foi possível concluir que a articaína é um anestésico local efetivo e seguro para uso na clínica odontológica, apresentando algumas vantagens sobre outros anestésicos locais comumente utilizados.

Palavras-chave: Anestesia local; Articaína; Epinefrina; Toxicidade. 


\begin{abstract}
Local anesthesia is commonly used in dentistry to perform procedures that involve pain. Currently available local anesthetics belong to the amide group and act by temporarily blocking the passage of nerve impulses. Articaine, despite being a relatively new anesthetic compared to others, has been widely used, showing several clinical benefits; however, it is a drug commonly associated with episodes of non-surgical paresthesia. The aim of this study was to review the literature on the use of articaine in dentistry, highlighting its clinical and molecular characteristics and possible complications arising from its use. The present work was carried out through a bibliographical research of scientific articles and books on the subject, seeking to know the supposed advantages and disadvantages of the use of articaine in dental procedures. Regarding the advantages, it has a high capacity to diffuse into the nerve cell, which allows for high success rates and short latency, in addition to a short half-life and longer duration of action, compared to the others local anesthetics. With regard to the supposed disadvantages, articaine has been commonly associated with an increased risk of non-surgical paresthesia, probably due to the higher concentration in which it is marketed, at $4 \%$. However, there is not enough evidence to confirm this relationship nor to refute it. It was possible to conclude that articaine is an effective and safe local anesthetic for use in the dental clinic, with some advantages over other commonly used local anesthetics.
\end{abstract}

Keywords: Local anesthesia; Articaine; Epinephrine; Toxicity.

\title{
Resumen
}

La anestesia local se usa comúnmente en odontología para realizar procedimientos que involucran dolor. Los anestésicos locales disponibles en la actualidad pertenecen al grupo de las amidas y actúan bloqueando temporalmente el paso de los impulsos nerviosos. La articaína, a pesar de ser un anestésico relativamente nuevo en comparación con otros, ha sido ampliamente utilizado, mostrando varios beneficios clínicos; sin embargo, es un fármaco comúnmente asociado con episodios de parestesia no quirúrgica. El objetivo de este estudio fue revisar la literatura sobre el uso de articaína en odontología, destacando sus características clínicas y moleculares y las posibles complicaciones derivadas de su uso. El presente trabajo se realizó a través de una búsqueda bibliográfica de artículos científicos y libros sobre el tema, buscando conocer las supuestas ventajas y desventajas del uso de articaína en procedimientos dentales. En cuanto a las ventajas, tiene una alta capacidad de difusión en la célula nerviosa, lo que permite altas tasas de éxito y una latencia corta, además de una vida media corta y una duración de acción más larga, en comparación con los demás anestésicos locales. Con respecto a las supuestas desventajas, la articaína se ha asociado comúnmente a un mayor riesgo de parestesias no quirúrgicas, probablemente debido a la mayor concentración en la que se comercializa, al 4\%. Sin embargo, no hay pruebas suficientes para confirmar esta relación ni para refutarla. Se pudo concluir que la articaína es un anestésico local eficaz y seguro para su uso en la clínica dental, con algunas ventajas sobre otros anestésicos locales de uso común.

Palabras clave: Anestesia local; Articaína; Epinefrina; Toxicidad.

\section{Introdução}

Os anestésicos locais são muito utilizados em odontologia em vários procedimentos, promovendo alívio de dor temporária, impedindo a condução do estímulo de dor das terminações nervosas periféricas para o Sistema Nervoso Central (Becker \& Reed, 2012). Os anestésicos classificados como amida são amplamente utilizados atualmente e seu mecanismo de ação é explicado pelo bloqueio dos canais de sódio, impedindo a etapa de despolarização da condução nervosa (Becker \& Reed, 2012; Moore \& Hersh, 2010). O cloridrato de articaína é o anestésico local mais recentemente introduzido no mercado odontológico e está disponível comercialmente para uso local na concentração de 4\%. É pertencente ao grupo amida, apesar de possuir um grupamento éster em sua molécula, possui meia-vida plasmática curta e alta taxa de ligação a proteínas plasmáticas (Victorino et al., 2004). Clinicamente, apresenta curto tempo de latência e duração de efeito intermediária (Malamed et al., 2000). Apesar do uso de anestesia local ser considerado seguro, existem alguns riscos de ocorrer efeitos adversos, como com qualquer outra droga, como efeitos sistêmicos: superdosagem, alergia ou idiossincrasia; e efeitos locais, como edema, trismo, hematoma e parestesia (Malamed, 2013).

Os anestésicos locais são normalmente comercializados com a adição de um vasoconstritor, o que permite aumento da duração do efeito, diminuição da toxicidade e melhor hemostasia (Moore \& Hersh, 2010). Dentre os vasoconstritores, a epinefrina é o mais comumente utilizado e está disponível em diversas concentrações (Lasemi et al., 2015).

O objetivo do presente trabalho é revisar a literatura acerca da utilização do anestésico local cloridrato de articaína $4 \%$ em odontologia. Objetiva-se, ainda, revisar as características químicas e moleculares da articaína, relatar a utilização clínica da 
articaína em odontologia, assim como suas vantagens e desvantagens, em comparação com os demais anestésicos utilizados; e expor as principais complicações advindas do uso de articaína, assim como as medidas preventivas.

\section{Metodologia}

O estudo foi realizado por meio da busca de artigos científicos e livros pertinentes à área e ao tema eleito. Os artigos científicos foram encontrados nas bases de dados Bireme, PubMed e Scielo mediante o uso dos seguintes descritores: “articaína; anestesia odontológica; articaína e lidocaína; articaína e mepivacaína; articaína e epinefrina; articaína e parestesia;”. Os mesmos descritores foram utilizados em língua inglesa: "articaine; dental anestesia; articaine and lignocaine; articaine and mepivacaine; articaine and epinephrine; articaine and paresthesia". Foram incluídos artigos em língua inglesa e artigos em língua portuguesa, desde o ano 2000 até os dias atuais, e que apresentavam revisão de literatura sobre o uso de articaína em odontologia e pesquisas referentes ao emprego do referido anestésico local, em comparação com outros fármacos semelhantes. Foram excluídos os artigos que apresentavam incompatibilidade com o tema, além de ausência ou falha de método do estudo.

\section{Resultados e Discussão}

\subsection{Propriedades químicas, moleculares e clínicas dos anestésicos locais}

Os anestésicos locais são classificados em dois grupamentos, éster e amida, sendo a articaína pertencente ao último. Independente da classificação, existe uma similaridade na molécula química dos compostos de ambos os grupos, apresentando um grupamento hidrofílico e um lipofílico. Entre eles, encontra-se a cadeia intermediária, responsável pela classificação em um dos dois grupos supracitados. Os anestésicos locais classificados como ésteres caracterizam-se por serem biotransformados no plasma por enzimas colinesterases, possuírem uma curta duração de efeito e apresentarem alto índice de reação alérgica pela formação de ácido para-amino-benzoico (PABA) em sua biotransformação. Os anestésicos locais do grupo amida caracterizam-se pela biotransformação hepática de forma mais complexa, serem absorvidos mais lentamente, possuírem um tempo de duração do efeito maior e serem praticamente isentos de reação alérgica (Malamed, 2013; Becker \& Reed, 2012; Moore \& Hersh, 2010). Os anestésicos locais disponíveis para uso odontológico, atualmente, são pertencentes ao grupo amida e seu mecanismo de ação pode ser explicado pela teoria do receptor específico, na qual os anestésicos locais se conectam a um receptor específico existente no lado interno da proteína canal de sódio impedindo a condução do impulso nervoso (Becker \& Reed, 2012).

De forma geral, os anestésicos locais são utilizados clinicamente associados a um vasoconstritor, o que traz algumas vantagens como retardo da absorção, com consequente aumento da duração do efeito; melhor controle hemostático e menor risco de toxicidade sistêmica (Moore \& Hersh, 2010). São classificados em dois grupos: das aminas simpatomiméticas, como a epinefrina, e grupo das aminas não simpatomiméticas, como a felipressina. Os pertencentes ao primeiro grupo atuam sistemicamente no organismo por meio da ligação a receptores adrenérgicos do tipo $\alpha$ e $\beta$; já o segundo grupo, atua diretamente sobre o músculo liso de revestimento dos vasos sanguíneos, promovendo sua contração (Malamed, 2013).

\subsection{Uso da articaína na odontologia}

A articaína foi o anestésico local mais recentemente introduzido no mercado brasileiro. Algumas características moleculares diferem a articaína dos demais anestésicos pertencentes ao grupo, como a presença de um anel tiofeno em sua molécula química, substituindo o anel benzeno normalmente existente, conferindo uma maior lipossolubilidade, que se manisfesta clinicamente com o aumento da potência e da capacidade de alcançar sucesso anestésico. Além disso, a articaína é o único anestésico local do grupo amida a possuir um grupamento éster em sua molécula química, e assim, possui duas vias de 
biotransformação, sendo metabolizada tanto no fígado, quanto pelas esterases plasmáticas. Tal particularidade contribui para seu tempo de meia-vida mais curto, e menor toxicidade (Abu-Mostafa et al., 2015; Becker \& Reed, 2012; Thakare et al., 2014; Victorino et al., 2004). A excreção da articaína é feita pelos rins (Malamed, 2013).

O mecanismo de ação da articaína é semelhante ao dos demais anestésicos do mesmo grupo. Classificado como um fármaco de base fraca, ao ser injetado, ocorrerá dissociação da molécula em forma iônica e forma molecular. A articaína é um anestésico local que apresenta duração intermediária do efeito anestésico e um rápido início de ação, devido ao seu baixo pKa de 7,8, o que faz com que seu tempo de latência seja reduzido (Snoeck, 2013; Yapp et al., 2011) (Bartlett \& Mansoor, 2016; Britto et al., 2014; Victorino et al., 2004). Sobre o tempo de duração anestésica, deve-se levar em consideração alguns fatores como, por exemplo, a difusão do anestésico através dos tecidos, o local da injeção, a técnica a ser feita e o uso dos vasoconstritores. De acordo com Moore et al. (2006) a solução de articaína a 4\% com epinefrina 1:100.000, apresenta, em técnica de bloqueio do nervo alveolar inferior, tempo de latência médio de 4,2 minutos e duração de anestesia pulpar de 61,8 minutos; para a técnica infiltrativa, a mesma solução apresenta 3 minutos de latência e 45 minutos de anestesia pulpar. Já a solução de articaína 4\% associada a epinefrina 1:200.000, na referida técnica de bloqueio exibe uma média de 4,7 minutos de latência e 51,2 minutos de duração de anestesia pulpar; em infiltração maxilar, os valores são, respectivamente, 3,1 e 41,6 minutos.

\subsection{Comparações entre articaína e outros anestésicos locais do grupo amida}

Diversos estudos já foram realizados, no sentido de comparar o efeito anestésico da articaína com os demais anestésicos locais do grupo amida. Por meio de revisão sistemática, Zang et al. (2019) demonstraram que, para bloqueio do nervo alveolar inferior, a solução de articaína $4 \%$ é superior à lidocaína $2 \%$, pois propicia maior taxa de sucesso, menor tempo de latência e maior duração do efeito. Já Soysa et al. (2019), também por meio de uma revisão sistemática, demonstraram que, para técnicas de bloqueio mandibulares, houve diferenças entre as mesmas duas soluções analisadas, mostrando superioridade para a articaína. Nas técnicas infiltrativas, houve superioridade da solução de articaína, tanto em maxila quanto em mandíbula, o que pode ser atribuído à sua maior capacidade de difusão para o interior da bainha nervosa. Ainda comparando as mesmas duas soluções anestésicas, Aggarwal et al. (2017) realizaram bloqueio do nervo alveolar inferior em molares inferiores com pulpite e não encontraram diferenças significativas no índice de sucesso entre as duas soluções. Provavelmente, esta ausência de diferenças seja justificada pelo fato de que, em elementos dentários com pulpite irreversível, o alcance da anestesia local é dificultado por conta da queda do $\mathrm{pH}$ dos tecidos, independentemente da solução utilizada.

Para avaliar o sucesso anestésico de técnicas infiltrativas na região posterior da mandíbula, Shapiro et al. (2018) compararam articaína $4 \%$ e lidocaína $2 \%$ em infiltração supraperiostal após falha do bloqueio do nervo alveolar inferior em molares inferiores com pulpite. Os resultados mostraram semelhança no sucesso obtido com ambas as soluções para o primeiro molar inferior e uma superioridade da articaína para o segundo molar inferior. Utilizando a mesma metodologia, Aggarwal et al. (2019) relataram ausência de diferenças significantes entre as duas soluções. Percebe-se que, tanto a solução à base de lidocaína quanto à base de articaína, podem aumentar o sucesso anestésico em um elemento posterior com pulpite após falha da técnica de bloqueio, tornando-se alternativas interessantes em casos de dificuldade para obtenção de anestesia satisfatória. Por outro lado, ao comparar injeções infiltrativas supraperiostais feitas com as mesmas soluções anestésicas para extração de elementos dentários não inflamados, Rayati et al. (2018) e Rathi et al. (2019) relataram maiores índices de sucesso com o uso de articaína 4\%, provavelmente devido a sua maior capacidade de difusão. Como os elementos dentários não apresentavam inflamação pulpar irreversível, a diferença entre a capacidade de difusão dos dois sais anestésicos tornou-se mais evidente nos resultados relativos a sucesso anestésico. 
A comparação entre bloqueio do nervo alveolar inferior com lidocaína $2 \%$ e infiltração supraperiostal com articaína 4\% em elementos posteriores mandibulares foi realizada por Narayanan et al. (2017), que encontraram que a técnica infiltrativa pode ser uma alternativa à técnica tradicional de bloqueio, uma vez que não foram vistas diferenças entre ambas. De modo semelhante, Bataineh \& Alwarafi (2016) demonstraram que a articaína 4\% apresenta índices de sucesso semelhante, tanto em infiltração na região posterior da mandíbula quanto em bloqueio do nervo alveolar inferior. Desta forma, por sua ampla capacidade de difusão, a articaína pode ser utilizada em infiltração supraperiostal, inclusive na mandíbula, mantendo os níveis de sucesso da técnica tradicional, mas propiciando uma menor área anestesiada.

\subsection{Articaína associada a diferentes concentrações de epinefrina}

Dentre os vasoconstritores utilizados associados aos anestésicos locais em odontologia, destaca-se a epinefrina, por conta de sua segurança e eficácia clínica. Ao ser injetada nos tecidos, seu efeito na rede vascular e, consequentemente, sobre a hemostasia e pressão arterial, depende de sua concentração. Quando presente em altas concentrações, a epinefrina conecta-se preferencialmente a receptores adrenérgicos do tipo $\alpha 1$, no qual promove vasoconstrição. À medida que a droga vai sendo biotransformada e excretada, sua concentração cai e a epinefrina passa a se ligar preferencialmente a receptores adrenérgicos do tipo $\beta 2$, no qual promove vasodilatação. Este efeito dúbio permite a manutenção de equilíbrio, sem que haja vasoconstrição excessiva e alterações importantes do ponto de vista cardiovascular (Malamed, 2013). Além disso, a epinefrina também pode atuar sobre receptores $\beta 1$, presentes principalmente no coração, sobre os quais promove aumento de frequência cardíaca e de pressão arterial (Abu-Mostafa et al., 2015).

Diante de todos estes efeitos sistêmicos, trabalhos anteriores compararam diferentes concentrações de epinefrina associada à articaína 4\%, com o intuito de elucidar uma solução anestésica que aliasse segurança e eficácia. Ao comparar as concentrações de 1:100.000 e 1:200.000 de epinefrina em associação à articaína 4\%, pode-se analisar tanto a eficácia anestésica quanto os parâmetros cardiovasculares. No que diz respeito à eficácia anestésica, a maioria dos trabalhos demonstra não haver diferenças significativas entre as duas formulações para o índice de sucesso anestésico alcançado. Estes resultados foram evidenciados em técnica de bloqueio do nervo alveolar inferior (De Morais et al., 2013; Lasemi et al., 2015), infiltrativa supraperiostal (McEntire et al., 2011) e infiltrativa intraóssea (Pereira et al., 2013). Por outro lado, Lima et al. (2013), encontraram que a solução de articaína 4\% com epinefrina 1:100.000 foi mais efetiva que a mesma solução anestésica com a epinefrina diluída pela metade. Possivelmente, esta diferença se deu por se tratar de extração de terceiros molares superiores com pericoronarite crônica, sendo que a presença do processo inflamatório pode alterar os índices de sucesso anestésico esperados.

Já para os parâmetros cardiovasculares, os resultados são um pouco mais diversos. No geral, não foram encontradas diferenças significativas quanto aos níveis de saturação de oxigênio com as duas soluções anestésicas (Abu-Mostafa et al., 2015; De Morais et al., 2013; Pereira et al., 2013). Quanto à frequência cardíaca, Lasemi et al. (2015) e Abu-Mostafa et al. (2015) não encontraram diferenças entre as soluções, enquanto que Pereira et al. (2013) e De Morais et al. (2013) relataram menores alterações com o uso do vasoconstritor mais diluído. Para a pressão arterial, alguns trabalhos evidenciaram ausência de diferenças entre as duas formulações (De Morais et al., 2013; Lasemi et al., 2015). Abu-Mostafa et al. (2015) relataram diferenças apenas para a pressão arterial sistólica, tendo esta menores níveis de alteração com epinefrina 1:200.000. Por outro lado, Pereira et al. (2013) apontaram que os valores de pressão arterial foram menores com o uso da epinefrina 1:100.000.

\subsection{Efeitos adversos}

O uso de anestésico local é considerado seguro, porém, como qualquer outra droga, existe risco de ocorrerem algumas complicações, sistêmicas ou locais. Dentre as complicações sistêmicas, podemos citar superdosagem, alergia e 
idiossincrasia (Malamed, 2013). Com relação às complicações locais, pode-se citar edema, trismo, hematoma e parestesia, dentre outras. A parestesia é definida pela perda sensorial da região inervada por um nervo lesado, geralmente provocada por um trauma direto durante a realização de um procedimento cirúrgico; entretanto, também pode ocorrer após procedimentos não cirúrgicos. Os possíveis fatores etiológicos envolvidos neste último caso seriam trauma direto causado pela penetração da agulha, compressão do nervo por hematoma após injeção ou neurotoxicidade inerente aos anestésicos locais. Demonstra-se que, usualmente, os casos de parestesia não cirúrgica ocorrem após a realização da técnica de bloqueio dos nervos alveolar inferior e lingual, sendo o nervo lingual mais comumente atingido (Gaffen \& Haas, 2009). (Garisto et al., 2010; Kakroudi et al., 2015).

Por ser comercializada em uma concentração mais elevada, a 4\%, alguns autores relacionam o uso de articaína a um maior risco de parestesia não cirúrgica. Diversos trabalhos retrospectivos já foram desenvolvidos, com base em casos de parestesia não cirúrgica relatados a órgãos responsáveis em diferentes países, como Canadá e Estados Unidos da América. Estes trabalhos demonstram que a articaína é responsável por grande parte dos casos de parestesia advinda da realização de anestesia local, sem procedimento cirúrgico associado. Essas taxas variam entre 41 e 60\%, aproximadamente, diferindo a articaína dos demais anestésicos de uso odontológico (Gaffen \& Haas, 2009; Garisto et al., 2010; Piccinni et al., 2015). Diferentemente, Stirrup \& Crean (2019), por meio de uma revisão sistemática, concluíram que não há evidências suficientes para afirmar que o risco de parestesia não cirúrgica é maior com o uso de articaína $4 \%$ do que com lidocaína $2 \%$.

Estes mesmos resultados não são vistos em estudos realizados com cultura de células neuronais. Malet et al. (2015) demonstraram que a articaína, assim como a ropivacaína, compõe o grupo dos anestésicos locais de menor neurotoxicidade, sendo esta menor que a apresentada por bupivacaína, lidocaína, prilocaína e mepivacaína. Do mesmo modo, Albalawi et al. (2018) relataram que a neurotoxicidade apresentada pela articaína $4 \%$ é semelhante à da lidocaína $2 \%$. Uma possível justificativa para as diferenças encontradas pelos estudos retrospectivos e os realizados em cultura de células, seja a quota de mercado pertencente à articaína. De fato, no ano de 2003, na Alemanha, a articaína era responsável por $70 \%$ de todos os anestésicos locais vendidos. Em outros países, como Estados Unidos da América e Canadá, essa quota varia entre 38 e $44 \%$. Considerando que este é o anestésico local mais recente no mercado e que existem, dependendo do país, no mínimo outras quatro opções de anestésicos locais, essas quotas representam uma fatia considerável do mercado.

É possível perceber que, apesar de mais nova no mercado brasileiro, a articaína apresenta diversas vantagens clínicas que justificam sua ampla utilização na clínica odontológica. Além disso, seu uso a 4\% demonstra-se seguro, tanto na formulação com epinefrina 1:100.000 quanto com a epinefrina 1:200.000, pois, apesar dos relatos de parestesia, ainda não existem evidências científicas suficientes para suportar tal relação.

\section{Conclusão}

Diante do que foi relatado, pode-se concluir que a articaína é um anestésico local efetivo, tanto para uso em técnicas de bloqueio, quanto para técnicas infiltrativas. Suas vantagens clínicas parecem justificar seu uso como primeira opção para a maioria dos pacientes odontológicos, principalmente os saudáveis. Além disso, demonstra ser uma droga segura, pois, apesar dos relatos acerca dos efeitos adversos, não há suporte científico suficiente para esta afirmação.

\section{Referências}

Abu-Mostafa, N., Al-Showaikhat, F., Al-Shubbar, F., Al-Zawad, K., \& Al-Banawi, F. (2015). Hemodynamic changes following injection of local anesthetics with different concentrations of epinephrine during simple tooth extraction: A prospective randomized clinical trial. Journal of Clinical and Experimental Dentistry, 7(4), e471-e476. https://doi.org/10.4317/jced.52321

Bartlett, G., \& Mansoor, J. (2016). Articaine buccal infiltration vs lidocaine inferior dental block - A review of the literature. British Dental Journal, 220(3), 117-120. https://doi.org/10.1038/sj.bdj.2016.93 
Becker, D. E., \& Reed, K. L. (2012). Local Anesthetics: Review of Pharmacological Considerations. Anesthesia Progress, 59(2), 90-102. https://doi.org/10.2344/0003-3006-59.2.90

Britto, A. C. S., Oliveira, A. C. A. DE, Lima, C. A. A., Souza, L. M. de A., Paixão, M. S., \& Groppo, F. C. (2014). Comparação da latência anestésica de Articaína, Lidocaína, Levobupivacaína e Ropivacaína através de "Pulp Tester." Revista de Odontologia Da UNESP, 43(1), 8-14. https://doi.org/10.1590/s1807-25772014000100002

De Morais, H. H. A., Holanda Vasconcellos, R. J., De Santana Santos, T., Rocha, N. S., Da Costa Araújo, F. A., \& De Carvalho, R. W. F. (2013). Clinical study of hemodynamic changes comparing $4 \%$ articaine hydrochloride with 1:100,000 and 1:200,000 epinephrine. Oral Surgery, Oral Medicine, Oral Pathology and Oral Radiology, 116(1), e14-e22. https://doi.org/10.1016/j.0ooo.2011.10.043

Dhimar, A. A., Sangada, B. R., Upadhyay, M. R., \& Patel, S. H. (2018). I-Gel versus laryngeal mask airway ( LMA ) classic as a conduit for tracheal intubation using ventilating bougie. 34(1), 467-472. https://doi.org/10.4103/joacp.JOACP

Gaffen, A. S., \& Haas, D. A. (2009). Retrospective Review of Voluntary Reports of. Journal (Canadian Dental Association), 75(8).

Garisto, G. A., Gaffen, A. S., Lawrence, H. P., Tenenbaum, H. C., \& Haas, D. A. (2010). Occurrence of paresthesia after dental local anesthetic administration in the United States. The Journal of the American Dental Association, 141(7), 836-844. https://doi.org/10.14219/jada.archive.2010.0281

Kakroudi, S. H. A., Mehta, S., \& Millar, B. J. (2015). Articaine hydrochloride: is it the solution? Dental Update, 42(1), 88-93. https://doi.org/10.12968/denu.2015.42.5.493

Lasemi, E., Sezavar, M., Habibi, L., Hemmat, S., Sarkarat, F., \& Nematollahi, Z. (2015). Articaine (4\%) with epinephrine (1:100.000 or 1:200.000 ) in inferior alveolar nerve block: Effects on the vital signs and onset, and duration of anesthesia. J Dent Anesth Pain Med, 15(4), 201-205.

Lima, J. L., Dias-Ribeiro, E., Ferreira-Rocha, J., Soares, R., Costa, F. W. G., Fan, S., \& Sant'ana, E. (2013). Comparison of buccal infiltration of 4\% articaine with $1: 100,000$ and $1: 200,000$ epinephrine for extraction of maxillary third molars with pericoronitis: a pilot study. Anesthesia Progress, 60(2), 42-45. https://doi.org/10.2344/0003-3006-60.2.42

Malamed, S. F. (2005). Manual de Anestesia Local (5a ed.). Elsevier Editora Ltda.

MALAMED, S. F. (2013). Manual de anestesia local (6a ed.)Elsevier.

Mcentire, M., Nusstein, J., Drum, M., Reader, A., \& Beck, M. (2011). as a Primary Buccal Infiltration in the Mandibular First Molar. Journal of Endodontics, 37(4), 450-454. https://doi.org/10.1016/j.joen.2010.12.007

Moore, P. A., Boynes, S. C., Hersh, E. V., DeRossi, S. S., Sollecito, T. P., Goodson, J. M., \& Hutcheson, M. (2006). The anesthetic efficacy of 4 percent articaine 1:200,000 epinephrine: Two controlled clinical trials. Journal of the American Dental Association, 137(11), 1572-1581. https://doi.org/10.14219/jada.archive.2006.0093

Moore, P. A., \& Hersh, E. V. (2010). Local Anesthetics: Pharmacology and Toxicity. Dental Clinics of North America, 54(4), 587-599. https://doi.org/10.1016/j.cden.2010.06.015

Pereira, L. A. P., Groppo, F. C., Bergamaschi, C. D. C., Meechan, J. G., Ramacciato, J. C., Motta, R. H. L., \& Ranali, J. (2013). Articaine (4\%) with epinephrine $(1: 100,000$ or $1: 200,000)$ in intraosseous injections in symptomatic irreversible pulpitis of mandibular molars: Anesthetic efficacy and cardiovascular effects. Oral Surgery, Oral Medicine, Oral Pathology and Oral Radiology, 116(2), e85-e91. https://doi.org/10.1016/j.0ooo.2011.10.045

Snoeck, M. (2013). Articaine: A review of its use for localand regional anesthesia. Local and Regional Anesthesia, 5(1), 23-33. https://doi.org/10.2147/LRA.S16682

Thakare, A., Bhate, K., \& Kathariya, R. (2014). Comparison of 4\% articaine and $0.5 \%$ bupivacaine anesthetic efficacy in orthodontic extractions: Prospective, randomized crossover study. Acta Anaesthesiologica Taiwanica, 52(2), 59-63. https://doi.org/10.1016/j.aat.2014.04.006

Victorino, F. R., Daniel, A. N., Iwaki Filho, L., Camarini, E. T., Mazucheli, J., \& Pavan, Â. J. (2004). Análise comparativa entre os anestésicos locais Articaína $4 \%$ e Prilocaína 3\% na extração de terceiros molares retidos em humanos. Acta Scientiarum - Health Sciences, 26(2), 351-356. https://doi.org/10.4025/actascihealthsci.v26i2.1588

Yapp, K. E., Hopcraft, M. S., \& Parashos, P. (2011). Articaine: a review of the literature. British Dental Journal, 210(7), 323-329. https://doi.org/10.1038/sj.bdj.2011.240 